\title{
Cascaded H-bridge Multilevel Inverter employing Front-end Flyback Converter with Single Independent DC Voltage Source
}

\author{
Ki-du Kim*, Gyou-tak Bae* and Feel-soon Kang**
}

\begin{abstract}
Cascaded H-bridge multilevel inverter requires independent DC voltage sources to produce multi output voltage levels. When it needs to generate more levels in the output voltage wave, the number of independent DC voltage sources usually limits its extension. To solve this problem, we propose a cascaded H-bridge multilevel inverter employing a frontend flyback converter for unifying input DC voltage sources. After theoretical analysis of the proposed circuit, we verify the validity of the proposed inverter using computer-aided simulations and experiments.
\end{abstract}

Keywords: Cascaded H-bridge Multilevel Inverter, Flyback Converter, Transformer, Inverters, Multilevel systems

\section{Introduction}

Cascaded H-bridge multilevel inverter has been studied for high voltage applications since it has merits in high reliability, modularity, and number of components [1]-[8]. Usually multilevel inverter is focusing on a generation of a high voltage using lower voltage rating devices connected in series. Also it has a potential advantage to get a high quality output voltage by producing multi levels in the output voltage wave. However, it increases the number of independent DC voltage sources and switching components resulted in the increase of complexity problem and system cost. To solve this problem, many researchers have been studied to reduce the number of components. However, it generally focuses on reducing the number of switching components [4]-[8].

In this paper, we present a cascaded H-bridge multilevel inverter adopting a front-end flyback converter to unify independent DC voltage sources. The flyback converter employs a transformer operated in high switching frequency, and it has one primary winding and two secondary windings. The secondary of the transformer in the general flyback converter consists of one diode and an output capacitor. In the proposed method, the diode is substituted for an active switch to control the output voltage in a constant value. Most of all, we can obtain our goal that is to drive the cascaded H-bridge multilevel inverter with a single independent DC voltage source. Because the

\footnotetext{
* Dept. of Control and Instrumentation Engineering, Hanbat National University, Korea.

** Dept. of Electronics and Control Engineering, Hanbat National University, Korea. (Corresponding Author: feelsoon@hanbat.ac.kr)

transformer is operated in high switching frequency, it does not increase size and volume of the system. After theoretical analysis, the validity of the proposed approach is proved by computer-aided simulations and experiments.

\section{Proposed approach for unifying independent input DC Voltage Sources}

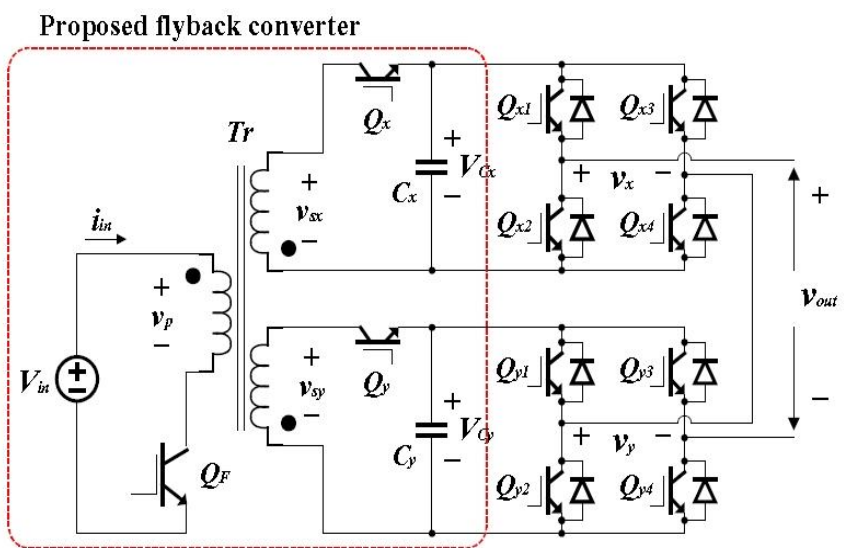

Fig. 1. Cascaded H-bridge multilevel inverter with the proposed front-end flyback converter.

Fig. 1 shows a circuit configuration of the cascaded Hbridge multilevel inverter with the proposed front-end flyback converter. The front-end flyback converter has a high frequency transformer which has two secondary windings to synthesize the upper and lower voltage sources. Amplitude of DC input voltage, duty ratio of switch QF, turn-ratio of the transformer determine voltage across two capacitors located in the secondary of the transformer. 


\subsection{Operational Mode}

Operational mode of the proposed flyback converter is divided into two modes due to the state of switch $Q_{F}$. Fig. 2 shows two operational modes. It includes a magnetizing inductance $\left(L_{m}\right)$ of the primary winding. The input current flows through the primary winding and the magnetizing inductance, when $Q_{F}$ is turned on and $Q_{x}$ and $Q_{y}$ are in off state. During this mode, there is no energy transfer to the secondary as shown in Fig. 2(a). And the magnetizing inductance saves energy for the next mode. At mode 2, $Q_{F}$ is turned off and $Q_{x}$ and $Q_{y}$ are turned on at the same time. Then the stored energy is transferred to the secondary of the transformer via the two secondary switches as shown in Fig. 2(b). During this period, $Q_{x}$ and $Q_{y}$ are automatically turned off, if voltage across the capacitor reaches to a preset voltage command value as given in Fig. 3. By this manner, voltage across the capacitor $\left(C_{x}\right.$ and $\left.C_{y}\right)$ is maintained in a constant value. If the secondary circuit of the flyback converter employs diodes instead of active switches like the traditional flyback circuit, it is impossible to maintain voltage across the capacitor constantly when the load is unbalanced.

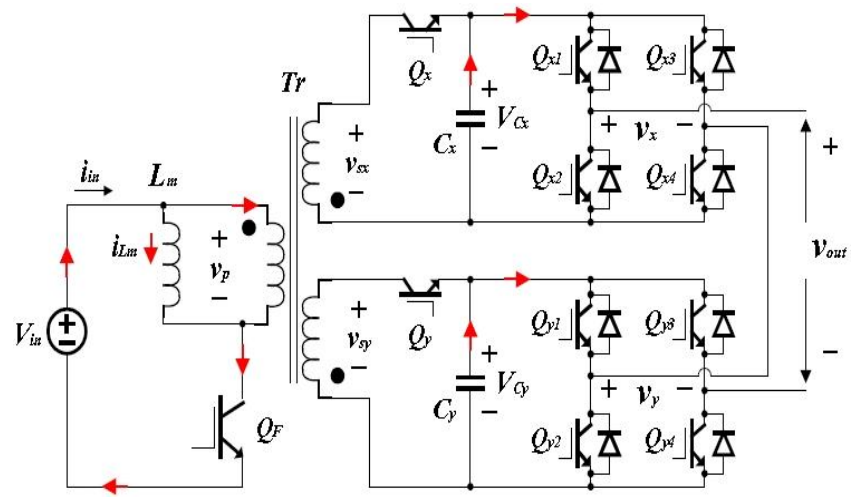

(a)

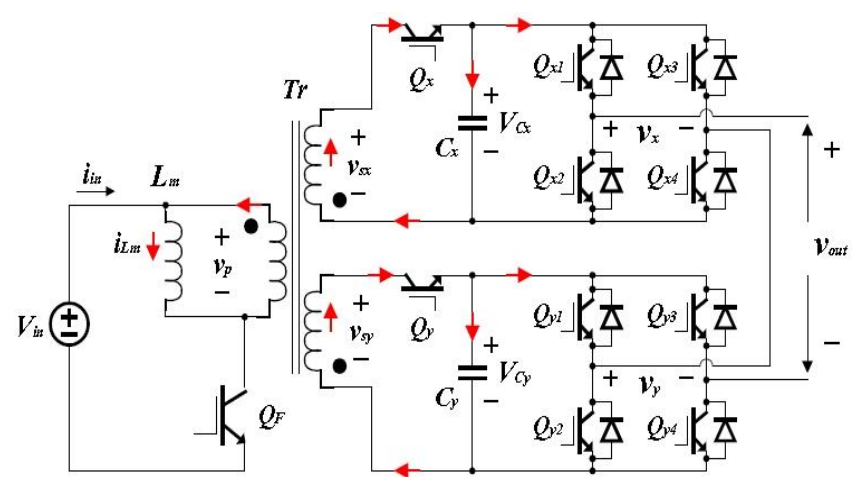

(b)

Fig. 2. Operational mode, (a) Mode 1, $Q_{F}=\mathrm{ON}$, (b) Mode 2, $Q_{F}=$ OFF.

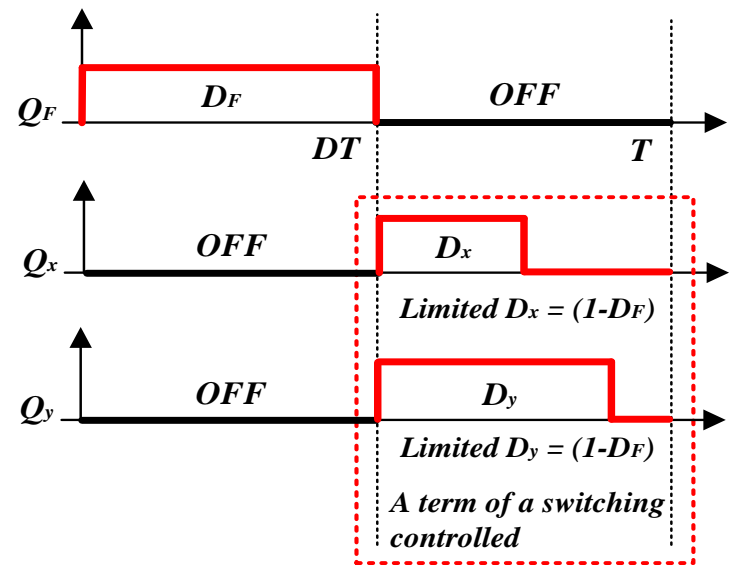

Fig. 3. Control signal for $Q_{F}, Q x$ and $Q y$

\subsection{Relationship Between Input and Output Voltage by Duty-ratio of $Q_{F}$}

Voltage across the capacitor in the secondary of the transformer is obtained by applying volt-sec. balance theory to the magnetizing inductance of the transformer.

$$
\begin{aligned}
& v_{c x}=\frac{N_{2}}{N_{1}} \cdot \frac{D_{F}}{D_{x}} \cdot V_{i n} \\
& v_{c y}=\frac{N_{2}}{N_{1}} \cdot \frac{D_{F}}{D_{y}} \cdot V_{i n}
\end{aligned}
$$

where, $V_{i n}$ is the input DC voltage. $D_{F}$ is duty ratio of $Q_{F}$. $D_{x}$ and $D_{y}$ are the duty ratio of the $Q_{x}$ and $Q_{y}$, respectively. $N_{l}$ and $N_{2}$ are turn ratio of the primary and the secondary windings of the transformer. To maintain the capacitor voltage constantly, it needs to control duty ratio of the switches $\left(Q_{x}\right.$ and $\left.Q_{y}\right)$. Each duty ratio of the switches is defined by

$$
D_{x(y)} \leq 1-D_{F}<0.5
$$

The secondary switches are working when the primary switch is turned off. And these switches are turned off when voltage across the capacitor reaches to a preset command value. Considering a pure resistive load, voltage ripple in each capacitor can be obtained by

$$
\begin{gathered}
\Delta v_{c y}=\frac{\Delta Q_{C x}}{C_{x}}=\frac{V_{C x} \cdot D_{F}}{R C_{x} \cdot f_{s}} \\
\Delta v_{c y}=\frac{\Delta Q_{C y}}{C_{y}}=\frac{V_{C y} \cdot D_{F}}{R C_{y} \cdot f_{s}}
\end{gathered}
$$


where, $\Delta Q$ means the variation of electric charge in a capacitor. $f_{s}$ is the switching frequency of $Q_{F}$. DF means the duty ratio of $Q_{F}$.

\section{Simulation Results}

To verify the validity of the proposed approach, we performed computer-aided simulations using PSpice. In this simulation, input voltage is set to DC 100[V], turn-ratio of the transformer is set to the same value so the output capacitor voltage is controlled by the duty ratio of the switch QF in a step-up condition. Switching frequency of all switches are $20[\mathrm{kHz}]$, and maximum duty cycle is limited at $24[\mu \mathrm{s}]$. The target output voltage of the multilevel inverter is set to AC 220[V], 60[Hz]. And it was considered to a pure resistive load.

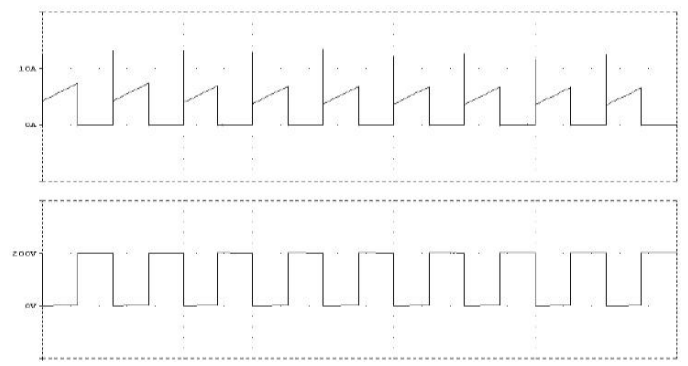

(a)

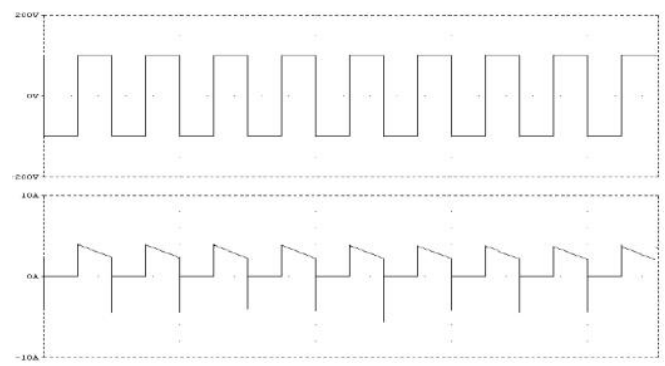

(b)

Fig. 4. Simulation results, (a) Drain current and voltage across the switch $Q_{F}$, (b) Secondary voltage of the transformer and switch $Q_{x}$ current.

Fig. 4(a) is simulation results for the primary switch $Q_{F}$. It shows a drain current of the switch $Q_{F}$ and voltage across the switch in sequence. Here, voltage stress of the switch $Q_{F}$ becomes twice of the input voltage because of the induced voltage from the secondary of the transformer. The secondary voltage of the transformer is given in the upper side of Fig. 4(b), and the lower waveform is a current flowing through the secondary switch $Q_{x}$. The source of the switch current is the energy stored in the magnetizing inductance during the prior mode. The duty cycle of $Q_{x}$ and $Q_{y}$ will be changed by the capacitor voltage depending on a load condition of multilevel inverter. In case of the switch $Q_{y}$, it has the same waveform when output capacitor voltage $C_{x}$ and $C_{y}$ have the same value.

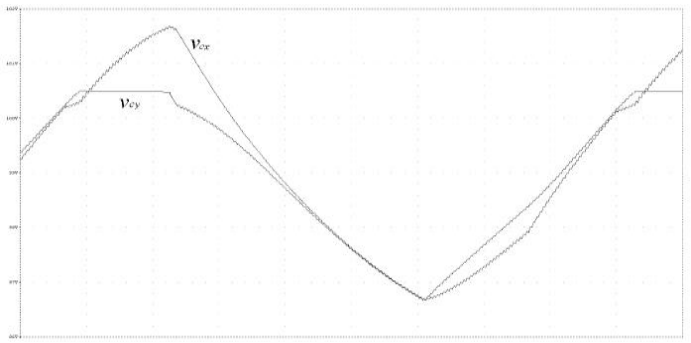

(a)

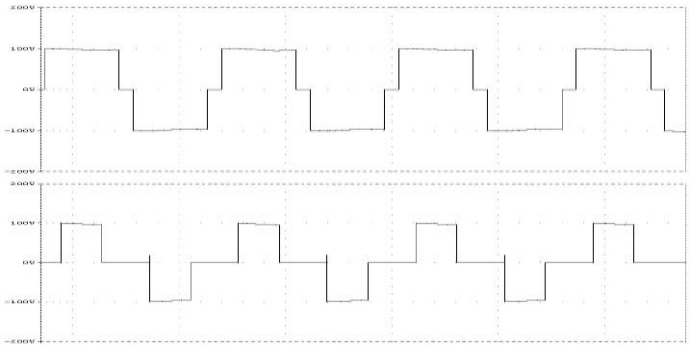

(b)

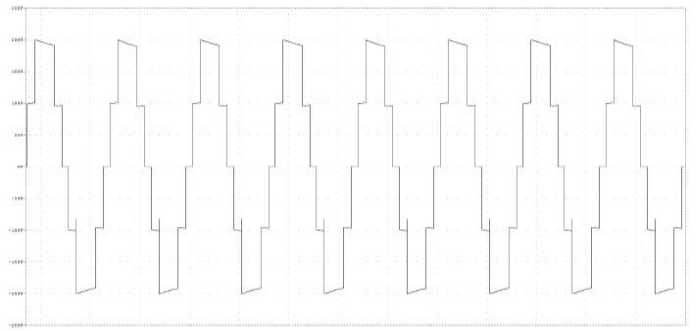

(c)

Fig. 5. Simulation results, (a) Voltage across the secondary capacitor $\left(v_{C x}\right.$ and $\left.v_{C y}\right)$, (b) Terminal voltage of each H-bridge module $\left(v_{x}\right.$ and $\left.v_{y}\right)$, (c) Output voltage $\left(V_{\text {out }}\right)$

Fig. 5(a) shows voltage across the secondary capacitor $\left(v_{C x}\right.$ and $\left.v_{C y}\right)$. The amplitude of the upper capacitor voltage $\left(v_{C x}\right)$ varies from $101.7[\mathrm{~V}]$ to 97.7 [V]. The maximum deviation is about 4 [V]. Because the target voltage of the capacitor is set to $100[\mathrm{~V}]$, we can say the voltage ripple is regulated in 4 [\%]. On the other hand, the amplitude of the lower capacitor voltage $(v c y)$ changes between 100.5 [V] and $97.7[\mathrm{~V}]$. Because the maximum deviation is about 2.8 [V], the voltage ripple of the lower capacitor is regulated in 2.8 [\%]. Fig. 5(b) shows terminal voltages of each H-bridge module. As shown in this figure, voltage ripple of the capacitor is slightly appeared in the terminal voltage waves. Fig. 5(c) shows an output voltage, which is synthesized by the sum of each H-bridge voltage. In this simulation, since we used two H-bridge module, the output voltage has five voltage levels. 


\section{Experiment Results}

To verify the validity of the proposed approach, we implemented experiments using a prototype. Input voltage is set to DC $48[\mathrm{~V}]$ by accumulation of 4 batteries of $12[\mathrm{~V}]$ connected in series. Switching device is Power MOSFET IRFP360 ( Vds $=400 \mathrm{~V}, \mathrm{Id}=23 \mathrm{~A}, \operatorname{Rds}(\mathrm{on})=0.20 \Omega$ ) by IXYS. EE7166 (AL value=9500) was used for high frequency transformer. DSP based controller was designed by TMS320F28335. Parameters are listed in Table. 1

Table 1. Parameters for a prototype.

\begin{tabular}{|c|c|}
\hline Parameter & Value \\
\hline Input voltage, $V_{\text {in }}$ & DC $48[\mathrm{~V}]$ \\
\hline Magnetizing inductance, $L_{m}$ & $300[\mu \mathrm{H}]$ \\
\hline Leakage inductance, $L_{\text {leakage }}$ & $2[\mu \mathrm{H}]$ \\
\hline Switching frequency, $f_{S}$ & $20[\mathrm{kHz}]$ \\
\hline Turns-ratio & $1: 1: 1$ \\
\hline Maximum Duty-ratio, $D$ & 0.4 \\
\hline Capacitor, $C_{x}, C_{y}$ & $1000[\mu \mathrm{F}]$ \\
\hline load & $200[\Omega]$ \\
\hline
\end{tabular}

Fig. 6 shows experiment results for voltage and current of switching devices. Fig. 6(a) shows voltage across QF and input current which is stored in the magnetizing inductance of the transformer during ON state of QF. When QF turns on, Qx and Qy are turned off. Therefore, there are no current flowing through Qx and Qy as shown in Fig. 6(b) and 6(c).

When QF turns off, Qx and Qy start to flow current depending on voltage levels of capacitor $\mathrm{Cx}$ and $\mathrm{Cy}$. By controlling of duty-ratio of Qx and Qy, voltage across Cx and $\mathrm{Cy}$ are maintained constantly.

Fig. 7 shows each terminal voltage ( $\mathrm{vx}$ and vy) of $\mathrm{H}-$ bridge module and output voltage (vout). The output voltage is controlled by PD (Phase disposition) method. Here, ma is set to 1 so voltage across $\mathrm{Cx}$ and $\mathrm{Cy}$ are controlled as 48[V]. Generally, cascaded H-bridge multilevel inverter generating 5-levels need two independent DC voltage sources. One is for generating Vdc level, and the other are used to generate $2 \mathrm{Vdc}$ voltage level, therefore, each DC voltage source has different power capacities. Hence, Vdc level is covered by capacitor $\mathrm{Cy}$, and $2 \mathrm{Vdc}$ is charged by $\mathrm{Cx}$. So voltage ripple of $\mathrm{Cy}$ is larger than that of $\mathrm{Cx}$. But in the proposed approach, voltage across Cx and Cy are controlled by Qx and Qy as in a constant value.

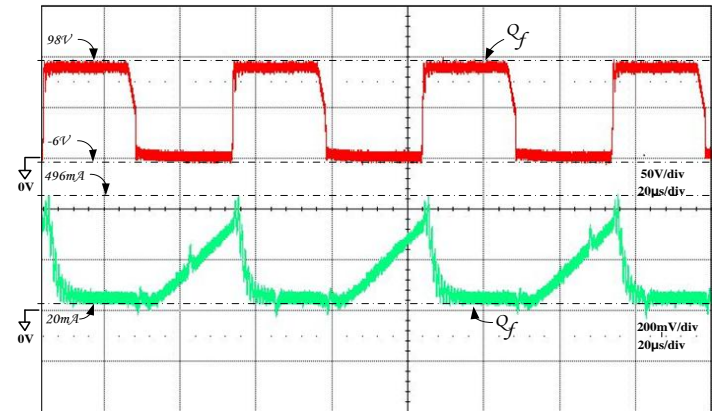

(a)

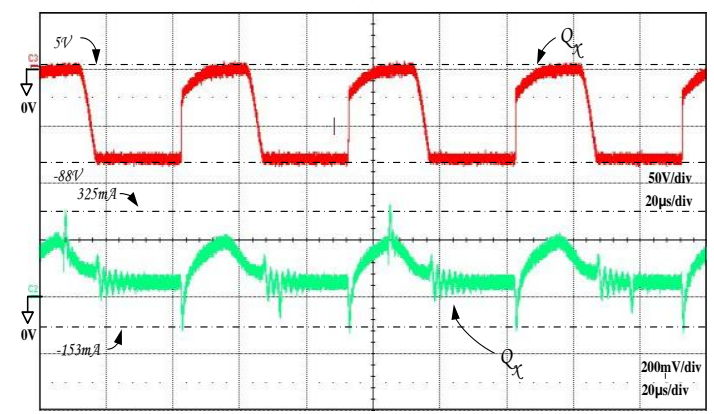

(b)

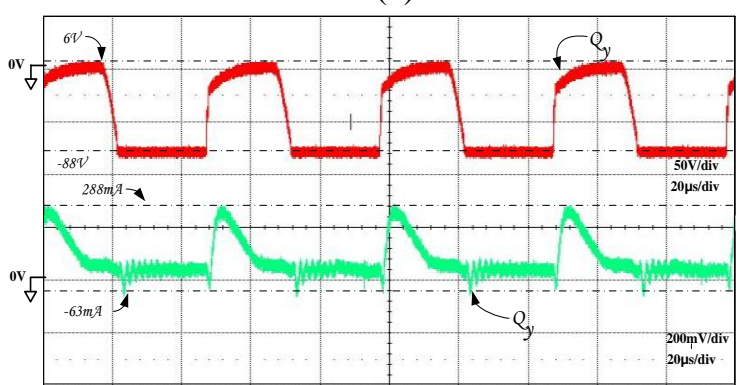

(c)

Fig. 6. Experiment results, (a) voltage across $Q_{F}$ and drain current of $Q_{F}$, (b) voltage across $Q_{x}$ and drain current of $Q_{x}$, (c) voltage across $Q_{y}$ and drain current of $Q_{y}$ from top to bottom.

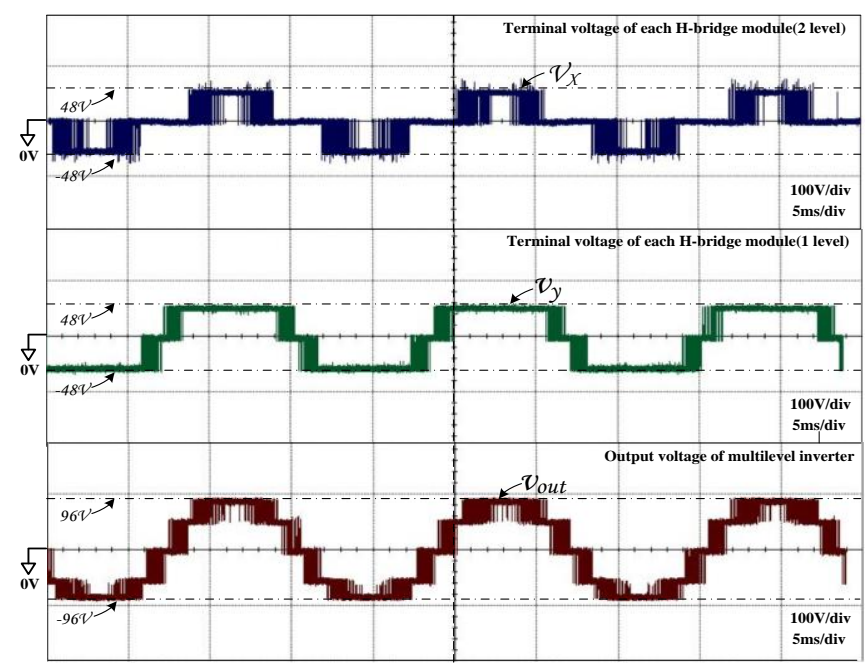

Fig. 7. Experiment results of $v_{x}, v_{y}$, and $v_{\text {out }}$. 


\section{Conclusion}

We proposed a cascaded H-bridge multilevel inverter employing a front-end flyback converter to unify independent DC voltage sources. Topologically, in the proposed approach, the diode of the general flyback converter is substituted for an active switch to control the output voltage in a constant value. Most of all, we can obtain our goal that is to drive the cascaded H-bridge multilevel inverter with a single independent DC voltage source without increasing size and volume of the system, since the transformer is operated in high switching frequency. After theoretical analysis, the validity of the proposed approach is proved by computer-aided simulations and experiment using a prototype.

\section{Acknowledgements}

This research was supported by Basic Science Research Program through the National Research Foundation of Korea (NRF) funded by the Ministry of Education, Science and Technology(No.2012-006120)

\section{References}

[1] L. G. Franquelo, J. Rodriguez, S. Kouro, R. Portillo, and M. A. M. Prats, "The age of multilevel converter arrives," IEEE Ind. Electron. Magazine, pp. 28-39, 2008.

[2] J. Rodriguez, J. S. Lai, and F. Z. Peng, "Multilevel Inverters: A survey of topologies, controls, and applications," IEEE Trans. Ind. Electron., vol. 49, no. 4, pp. 724-738, Aug. 2002.

[3] Tolbert L. M. et. al., 1999, Multilevel converters for large electric drives, IEEE Trans, Ind. Appl., vol. 35, no. 1, pp. 3644.

[4] Kang, F. S. et. al., 2005, An efficient multilevel synthesis approach and its application to a 27-level inverter, IEEE Trans. Ind. Electron., vol. 52, no. 6, pp. 1600-1606.

[5] Song, S. G., et. al., 2009, Cascaded Multilevel Inverter Employing Three-Phase Transformers and Single DC Input, IEEE Trans. Ind. Electron., vol. 56, no. 6, pp. 2005- 2014.

[6] Lai, J.-S. et. al., 1996, Multilevel converters-A new breed of power converters, IEEE Trans. Ind. Appl., vol. 32, no. 3, pp. 509-517.

[7] Franquelo, L. G. et. al., 2008, the age of multilevel converters arrives, IEEE Ind. Electron. Mag., vol. 2, no. 2, pp. 28-39.

[8] Abu_Rub, H. et. al., 2010, MediumVoltage Multilevel converters State of the Art, Challenges, an $\mathrm{d}$ Requirements in Industrial Applications, IEEE Trans. Ind. Electron., vol. 57, no. 8, pp. 2581-2596.

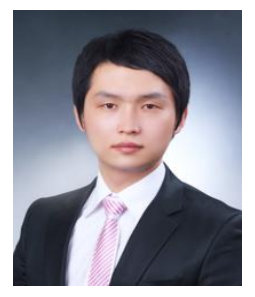

Ki-du Kim received the B.S. degrees in the Department of Control and Instrumentation Engineering, Hanbat National University, Daejeon, Korea in 2012. He is currently working toward M.S. degree at the same university. His research interests are in the fields of power electronics including design and control of power converters for electric vehicles. Mr. Kim is a member of KIEE and KIPE.

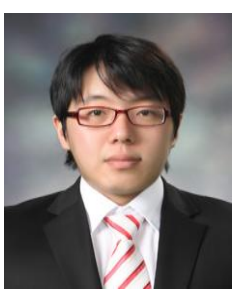

Gyou-tak Bae received B.S. degrees in the Department of Control and Instrumentation Engineering at Hanbat National University, Daejeon, Korea in 2013. He is currently working toward M.S. degree at the same university. His research interests are in the area of power electronics including design and control of power converters for electric vehicles. Mr. Park is a member of KIEE and KIPE.

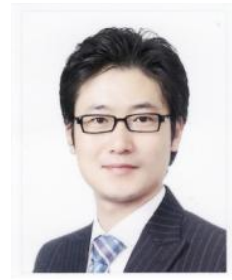

Feel-soon Kang received M.S. and Ph.D degrees from Pusan National University, Busan, Korea in 2000 and 2003, respectively. From 2003 to 2004, he was with the Department of Electrical Engineering, Osaka University, Osaka, Japan as a Post-doctoral Fellow. Since 2004, he has been with the Department of Electronics and Control Engineering, Hanbat National University, Daejeon, Korea as an associate professor. From 2012 to 2013, he is a visiting professor in the Department of Electrical and Computer Engineering, Colorado State University. His research activities are in the area of power electronics including design and control of power converters for electric vehicles, and multilevel inverters for photovoltaic power generating systems. He received an Award from IEEE Industrial Electronics Society and the Best Presentation Prize at IEEE IECON'01 held in Denver, Colorado USA in 2001. He was honored an Academic Award from Graduate School of Pusan National University and Hanbat National University in 2003 and 2005, respectively. And he also received several Best Paper Awards from KIPE, KIEE, and KIMICS. He served as Cochairs and secretary for ICEMS 2010, MAGLEV 2011, VPPC 2012, and other domestic and international conferences. Dr. Kang is Associate Editor of JICEMS. 